\title{
Beliefs and Attitudes Among Italian High School Students Toward People With Severe Mental Disorders
}

\author{
Marianna Serra, PsyD, * Alessandra Lai, PsyD, * Chiara Buizza, PsyD, $\dagger$ Rosaria Pioli, MD, $\dagger$ \\ Antonio Preti, MD, *; $\$$ Carmelo Masala, MD, *; $;$ and Donatella Rita Petretto, PsyD*; $\neq$
}

\begin{abstract}
The negative attitudes surrounding mental disorders and their treatment are a major obstacle to the correct identification and treatment of emerging psychopathologies. The purpose of this study was to investigate mental health literacy in a large and representative sample of high school students in Italy, via a booklet containing several questionnaires delivered to 1032 teenagers. The items in the questionnaires probed knowledge about mental health and illness, stigmatization, stereotypes, behaviors, opinions, and attitudes. In general, the students had a reasonable knowledge of mental disorders and were able to distinguish these from somatic disorders. However, a large portion of the students nourished some misconceptions about mental disorders and was also rather skeptical about the effectiveness of treatment or the chance of recovery for people with severe mental disorders. Nevertheless, roughly half of the students reported being willing to provide help to someone with a mental disorder when in need. Poor mental health literacy is a major barrier to seeking help and receiving effective treatment. Young people are the ideal target of raising awareness and antistigma campaigns because they are at a higher risk for developing a psychopathology.
\end{abstract}

Key Words: Young people, stigma, beliefs, mental health literacy, schizophrenia, violence

(J Nerv Ment Dis 2013;201: 311-318)

$\mathrm{M}$ any mental disorders diagnosed in adulthood have their onset in childhood or adolescence (Kessler et al., 2007; Kim-Cohen et al., 2003). For this reason, the early detection of mental disorders and the delivery of effective interventions during these phases of individual development are essential to prevent the worst outcomes of psychopathology (Patton et al., 2007). Moreover, mental disorders that begin during childhood and adolescence have a negative impact on the development of the affected young people and hamper their present and future functioning and well-being (Costello et al., 1999).

Negative attitudes toward mental disorders and their treatment are a major obstacle to the correct identification and treatment of emerging psychopathologies. People often refrain from finding the support and the care they need for fear of having negative labels attached to them by relatives or friends as a result of their mental health status (Angermeyer and Matschinger, 2003; Thornicroft, 2008). Negative attitudes are particularly strong against the use of drugs to treat mental disorders (Jenkins and Carpenter-Song, 2009; Sorsdahl and Stein, 2010). For example, the use of antidepressants to treat

*Department of Education, Psychology, Philosophy, University of Cagliari, Cagliari, Italy; $\dagger$ IRCCS Centro S. Giovanni di Dio-Fatebenefratelli, Brescia, Italy; $₫$ Associazione Centro Studi Ricerche ed Intervento "Neuropsicopedagogia" Onlus, Cagliari, Italy; and §Genneruxi Medical Center, Cagliari, Italy.

Send reprint requests to Alessandra Lai, PsyD, Department of Education, Psychology, Philosophy, University of Cagliari, via Is Mirrionis 1, 09123 Cagliari, Italy. E-mail: alessandralai1@gmail.com; Marianna Serra, PsyD, Department of Education, Psychology, Philosophy, University of Cagliari, via Is Mirrionis 1, 09123 Cagliari, Italy. E-mail: serramarianna@yahoo.it.

Copyright (C) 2013 by Lippincott Williams \& Wilkins

ISSN: 0022-3018/13/20104-0311

DOI: $10.1097 / \mathrm{NMD} .0 \mathrm{~b} 013 \mathrm{e} 318288 \mathrm{e} 27 \mathrm{f}$ depression is often perceived as a sign of emotional weakness and inability to deal with problems (Castaldelli-Maia et al., 2011).

The complex interplay of ignorance and misinformation, negative attitudes and prejudice, and excluding or avoiding behaviors (i.e., discrimination) that surround people who have been diagnosed with a mental disorder is referred to as stigma (Corrigan, 2004; Thornicroft et al., 2007). The word stigma comes from an ancient Greek word meaning mark or scar, that is, a disfiguring and identifying sign on the body. Stigma acts as a powerful force of exclusion and negatively affects the life of those who have mental disorders and their families (Corrigan, 2004; Thornicroft et al., 2007). A greater stigma is attached to the most severe mental disorders, especially schizophrenia and its related psychoses (Angermeyer and Matschinger, 1997; Norman et al., 2008). Patients diagnosed with psychosis have the greatest chance of marginalization and discrimination because of the stigma attached (Buizza et al., 2007), and stigmatization per se exerts a negative influence on both the course and the outcome of the disorder (van Zelst, 2009). There is evidence that stigma against mental disorders seriously impacts the will of young people to seek help for their mental health difficulties (Fröjd et al., 2007; Mukolo et al., 2010; Pescosolido et al., 2008; Quinn et al., 2009; Yap and Jorm, 2011). Young males, in particular, are influenced by negative attitudes and beliefs about mental disorders, with higher stigmatizing attitudes associated with lower recourse to both clinical and nonclinical sources of support (Eisenberg et al., 2009; Gonzalez et al., 2005).

Ignorance, which is derived from a lack of knowledge, and prejudice, which is based on negative attitudes, are two important components of stigma but could be both changed by interventions aimed at increasing knowledge and reducing negative attitudes (Rutz, 2001; World Psychiatric Association, 2000). Young people are the ideal targets of raising awareness and antistigma campaigns because they are at a higher risk for developing a psychopathology, and they may benefit from interventions targeted at increasing their willingness to access treatment when in need. Moreover, they are the citizens of the future and will influence public-health decisions by expressing their attitudes and beliefs (Pinto-Foltz and Logsdon, 2009; Warner, 2008).

The assessment of mental health literacy, that is, knowledge and beliefs about mental disorders and their treatment (Jorm et al., 1997), is now considered a preliminary step in evaluating the effectiveness of raising awareness and antistigma campaigns because it has been related to personal stigma and discrimination (Griffiths et al., 2008) and was found to mediate changes in attitudes and beliefs about mental disorders (Kelly et al., 2007; Wolff et al., 1996). For this reason, some authors consider mental health literacy an outcome per se, that is, an increase in mental health literacy is expected to lower stigma and discrimination (Evans-Lacko et al., 2010). Poor mental health literacy is a major barrier to seeking help and receiving effective treatment (Jorm, 2012). From this, one can infer that improving mental health literacy directed at young people may help to prevent the worst consequences of poor knowledge related to mental disorders. Indeed, there is evidence that participation in educational programs that teach about mental disorders can help to inform beliefs about these and improve attitudes toward those who 
have mental disorders and, as an indirect consequence, eliminate barriers for those seeking help and/or receiving effective treatment (Corrigan et al., 2001; Penn et al., 1994; Sakellari et al., 2011). However, the long-term effects of these educational programs among the young people and the impact on those seeking help are still unclear (Yamaguchi et al., 2001).

This is the first study on mental health literacy carried out among students in Italy. Past investigations focusing on this topic were based on pilot studies intended to test the feasibility of a protocol or the validity of a questionnaire (Buizza et al., 2010; Mirabella et al., 2010; Pingani et al., 2012; Vezzoli et al., 2001).

We expected that those who were less likely to correctly distinguish mental disorders from somatic disorders would report less favorable attitudes, hence greater stigma, toward people diagnosed with psychosis and would be less willing to provide help to someone affected by a mental disorder. In addition, female and younger participants were expected to report less stigma toward people diagnosed with psychosis. Indeed, there is some evidence that social distance and stigmatizing attitudes are higher in males and are negatively related to age (Chandra and Minkovitz, 2006; Jorm and Wright, 2008; Wang et al., 2007).

\section{METHODS}

The survey was carried out in late October 2010 as part of a study aimed at investigating knowledge, beliefs, and attitudes of high school students toward people with mental disorders. The Regional Authority of Sardinia financed and authorized the study named FUMO: Fight for the Future: Understanding and Modifying Stigma of Mental Illness. The appropriate institutional review boards (of the local university department performing this study and of the involved high schools) approved the protocol of this study, which complies with the provisions of the 1995 Declaration of Helsinki (as revised in Tokyo, 2004). The teachers and the parents of the students were asked first to give their consent to include the selected students in this study, and, upon their consent, the students were then asked to provide their own informed consent.

\section{Study Sample and Procedure}

Included in the study were 1,077 students from the last three grades (III, IV, and V) of four large high schools (two scientific high schools and two technical high schools) operating in the district of Cagliari, the main town (about 300,000 inhabitants) of Sardinia. A total of 1,032 students were at school during the collection of data, and 1,023 participants provided full information (94\% response rate). At the time of the study, the area covering the sample had a total of 16,660 males and 15,558 females within the age interval of the participants. In Sardinia, about $85 \%$ of all teenagers attend high school upon the conclusion of compulsory studies. The participant sample therefore included around $4 \%$ of all adolescents attending a high school in the area.

The students were invited to take part in a study on knowledge about mental disorders and their treatment. Sitting quietly in their classrooms, the students received a booklet containing the following: a questionnaire to be completed with personal background information, a questionnaire on the knowledge of mental disorders, and a questionnaire investigating beliefs and attitudes toward people diagnosed with psychosis.

All questionnaires were part of a booklet developed by the Istituto Superiore di Sanità, that is, the Italian National Institute of Health, to assess the beliefs and the attitudes of young people toward those with mental disorders, within the framework of a schoolbased mental health promotion program (Mirabella et al., 2010).

\section{Background Information}

The questionnaire used to collect personal background information of the study's participants asked about sex, age, contact with relatives and friends, and each student's personal experience with people showing the most frequent symptoms of mental disorder (e.g., low self-esteem,suicide ideation, social withdrawal, auditory hallucinations).

Two questions asked about the participants' social networking habits:

a) How many relatives do you visit at least once every 6 months?

b) How many friends do you see at least once per week?

The personal experience of each participant with people showing symptoms of mental disorder was investigated with the open question "How many people do you know who ..." and a list of 14 descriptions of the most common symptoms of mental disorder (see Table 1 for details). History of psychosis in relatives was established according to the responses to three questions inquiring about hallucinations (item 10), psychotic-like beliefs (item 11), and paranoid thinking (item 12) as well as a more detailed description of a case with symptoms of psychosis (item 14).

\section{Knowledge of Mental Disorders}

The questionnaire on the participants' knowledge of mental disorders was aimed at assessing the students' knowledge on the names of the major mental disorders (e.g., major depression, schizophrenia, panic attack) and the students' ability in differentiating them from somatic disorders (e.g., acquired immunodeficiency syndrome [AIDS]). The responses to the knowledge questionnaire were evaluated by item, as described in Table 3. The unidimensionality of the questionnaire on the knowledge of mental disorders was formally tested with a confirmatory factorial analysis (CFA; see below). The CFA yielded a reasonably acceptable fit for the unidimensional structure of the questionnaire when considering the items on mental disorders only (see Results and Table 3). Therefore, a summary score was derived by summing the number of corrected replies on the items on mental disorders (each corrected reply counting as 1).

\section{Beliefs and Attitudes Toward People Diagnosed With Psychosis}

The questionnaire used to analyze beliefs and attitudes toward people diagnosed with psychosis was the study's measure of stigma. This questionnaire included a case vignette to detail the symptoms of those diagnosed with psychosis:

A person with psychosis is someone who shows four of or more of these problems: odds beliefs or ideas, which none of his/ her acquaintances can share; hearing voices or seeing things which none else can hear or see; social withdrawal; severe impairment of the ability of studying or working; lack of initiative or willingness to do things; feelings of persecution or being victim of a conspiracy.

The participants were then asked about potential benefits of treatment of people with psychosis, chances of recovery, dangerousness, risk for victimization, ability to find and stay in paid employment, and need for admission to a closed hospital (see Table 4 for details). The scores on this questionnaire followed the Likert format (1-5), from "none" to "the majority," except for the questions on dangerousness and the need for admission to a closed hospital, for which the scores were reversed (i.e., "none" replies were rated 5, "the majority" replies were rated 1). On each item, lower scores corresponded to more stigmatizing attitudes.

The unidimensionality of the questionnaire investigating beliefs and attitudes toward people diagnosed with psychosis was formally tested with CFA (see below). The CFA yielded a reasonably acceptable fit for the unidimensional structure of the questionnaire 
TABLE 1. Personal Experience With People Showing Symptoms Indicative of Mental Disorders

\begin{tabular}{|c|c|c|c|c|c|c|}
\hline \multirow{2}{*}{ Do you know people who ... } & \multicolumn{2}{|c|}{$\begin{array}{c}\text { Among } \\
\text { Relatives }\end{array}$} & \multicolumn{2}{|c|}{$\begin{array}{l}\text { Among } \\
\text { Friends }\end{array}$} & \multicolumn{2}{|c|}{$\begin{array}{l}\text { Among } \\
\text { Classmates }\end{array}$} \\
\hline & 1 & $\geq \mathbf{2}$ & 1 & $\geq \mathbf{2}$ & 1 & $\geq 2$ \\
\hline $1 . .$. have low or no self-esteem? & $105(10 \%)$ & $140(14 \%)$ & $170(17 \%)$ & $224(22 \%)$ & $157(15 \%)$ & $313(30 \%)$ \\
\hline $\begin{array}{l}\text { 2. ... have lost the desire to do things } \\
\text { and tend to do nothing all day? }\end{array}$ & $165(16 \%)$ & $129(13 \%)$ & $163(16 \%)$ & $232(23 \%)$ & $116(11 \%)$ & $235(23 \%)$ \\
\hline 3. ... are discontented with their lives? & $67(7 \%)$ & $46(4 \%)$ & $48(5 \%)$ & $68(6 \%)$ & $58(6 \%)$ & $56(5 \%)$ \\
\hline $\begin{array}{l}\text { 4. ... have attempted suicide or seriously } \\
\text { hurt themselves within the past } 24 \text { months? }\end{array}$ & $35(3 \%)$ & $7(1 \%)$ & $55(5 \%)$ & $16(2 \%)$ & $21(2 \%)$ & $5(0.5 \%)$ \\
\hline $\begin{array}{l}\text { 5. ... have unjustified fears (so-called phobias) } \\
\text { that condition their behavior }\end{array}$ & $163(16 \%)$ & $133(13 \%)$ & $201(20 \%)$ & $176(17 \%)$ & $150(15 \%)$ & $172(17 \%)$ \\
\hline $\begin{array}{l}\text { 6. ... keep to themselves and almost never spend } \\
\text { time with other people (social withdrawal)? }\end{array}$ & $110(11 \%)$ & $51(5 \%)$ & $111(11 \%)$ & $57(5 \%)$ & $161(16 \%)$ & $95(9 \%)$ \\
\hline $\begin{array}{l}\text { 7. ... feel the need to repeat the same actions over } \\
\text { and over (for example, wash up frequently or check } \\
\text { the same things repeatedly), even if this behavior } \\
\text { serves no purpose? }\end{array}$ & $125(12 \%)$ & $64(6 \%)$ & $92(9 \%)$ & $75(7 \%)$ & $62(6 \%)$ & $64(6 \%)$ \\
\hline $\begin{array}{l}\text { 8. ... do all they can to lose weight or stay thin, even } \\
\text { if they are already underweight? }\end{array}$ & $101(10 \%)$ & $57(5 \%)$ & $169(16 \%)$ & $111(11 \%)$ & $114(11 \%)$ & $102(10 \%)$ \\
\hline $\begin{array}{l}\text { 9. ... have health problems or troubled social lives at school } \\
\text { and/or at work due to the use and abuse of alcohol } \\
\text { and/or other drugs? }\end{array}$ & $56(6 \%)$ & $25(2 \%)$ & $73(7 \%)$ & $145(14 \%)$ & $44(4 \%)$ & $69(7 \%)$ \\
\hline $10 . .$. often hear voices which no-one else can hear? & $34(3 \%)$ & $16(2 \%)$ & $40(4 \%)$ & $31(3 \%)$ & $37(4 \%)$ & $15(1 \%)$ \\
\hline $\begin{array}{l}\text { 11. ... have odds beliefs or ideas, which none of his/her } \\
\text { acquaintances can share? }\end{array}$ & $101(10 \%)$ & $43(4 \%)$ & $134(13 \%)$ & $85(8 \%)$ & $138(14 \%)$ & $74(7 \%)$ \\
\hline 12. ... have feelings of persecution or being victim of a conspiracy? & $89(9 \%)$ & $26(2 \%)$ & $80(8 \%)$ & $51(5 \%)$ & $95(9 \%)$ & $48(5 \%)$ \\
\hline $\begin{array}{l}\text { 13. ... are domineering with other people and enjoy } \\
\text { humiliating and/or hurting them? }\end{array}$ & $50(5 \%)$ & $20(2 \%)$ & $82(8 \%)$ & $155(15 \%)$ & $102(10 \%)$ & $127(12 \%)$ \\
\hline $\begin{array}{l}\text { 14. ... have four or more of the following problems: } \\
\text { hearing voices or seeing things which none else can } \\
\text { hear or see; social withdrawal; severe impairment } \\
\text { of the ability of studying or working; lack of initiative } \\
\text { or willingness to do things; feelings of persecution or } \\
\text { being victim of a conspiracy? }\end{array}$ & $49(5 \%)$ & $12(1 \%)$ & $52(5 \%)$ & $47(5 \%)$ & $37(3 \%)$ & $49(5 \%)$ \\
\hline
\end{tabular}

(see Results and Table 4). Therefore, the scores on each item of the questionnaire investigating beliefs and attitudes toward people diagnosed with psychosis were summed to give a general measure of nonstigmatizing attitudes, with lower scores on this questionnaire considered to be evidence of stigma held against people diagnosed with psychosis.

\section{Willingness to Provide Help to Someone With a Mental Disorder}

A final question asked about the willingness to provide help to someone with a mental disorder when in need, a proxy for social distance, or the propensity to interact with a target person in different types of relationships (see Link et al., 2004).

\section{Statistics}

Data (with the exception of CFA) were analyzed using the Statistical Package for Social Science (SPSS) for Windows (Chicago, IL 60606), version 13.

All tests were two tailed. Because of multiple testing, threshold of significance was set at $p<0.0001$; according to Bayesian interpretations, this threshold has the highest chance of confirmation in future studies (Katki, 2008). Categorical data were analyzed in intergroup comparisons with chi-square or Fisher's exact test, when appropriate ( $n<5$ in any cell in contingency tables). The $t$-test was used for continuous variables (e.g., age); the Mann-Whitney's $U$-test was used to compare the ordinal variables. Spearman's rho correlation coefficients were used to examine associations between variables.

CFA was carried out using EQS-structural equation modelling software (Multivariate Software, Inc, Encino, Calif) for Windows version 6.1 (Bentler, 2008). Maximum likelihood under elliptical distribution was used to estimate fit. Chi-square is the traditional fit index for evaluating the overall model fit because it assesses the magnitude of discrepancy between the sample and fitted covariance matrices (Hu and Bentler, 1999, p. 2). However, the use of the chisquare likelihood ratio test to assess model fit was found unsatisfactory for a number of reasons, including sensitivity to sample size (Tanaka, 1993). Therefore, it has become habitual in testing CFA models to rely on the rather liberal $\mathrm{Hu}$ and Bentler (1999) criteria. The following criteria for fit were applied: the comparative fit index (CFI), the root mean square error of approximation (RMSEA), and the standardized root mean square residual (SRMR). The RMSEA values of less than 0.06 indicate a good fit; however, values as high as 0.08 were considered indicative of a reasonable fit $(\mathrm{Hu}$ and Bentler, 1999). SRMR values 0.09 or lower and CFI values 0.90 or higher are considered acceptable (Browne and Cudeck, 1993; $\mathrm{Hu}$ and Bentler, 1999). A factor loading of 0.32 or higher $(10 \%$ of variance) was considered the minimum requirement for an item to be included in the final global score (Comrey, 1973).

Scale reliability was measured using the maximal weighted internal consistency reliability from the CFA testing unidimensional model (Bentler, 2008). To compare groups, reliability values 
of 0.70 were considered satisfactory (Bland and Altman, 1997); however, when dealing with subscales derived from a single questionnaire, values around 0.60 were considered acceptable (Nunnally, 1978).

\section{RESULTS}

\section{General Results}

The sample included an equal proportion of male and female participants: 506 male participants $(49 \%)$ and 517 female participants $(51 \%)$. The mean (SD) age in the sample was $17.3(1.3)$ years (range, 15-24 years), with no difference by sex; about two thirds of the students were 17 years or older (Table 2).

In the sample, family social networks were comparable between the male and female participants, but the female participants tended to have a smaller and, in all likelihood, more focused social network as far as friendship was concerned. In the sample, the number of relatives that the participants visited at least once every 6 months had a positive correlation with the number of friends they saw on a weekly basis (Spearman's $\rho=0.198, p<0.0001$ ).

A trend emerged that negatively associated age with the number of relatives visited (Spearman's $\rho=-0.107, p=0.001$ ), but the finding was lower than the predefined threshold to be considered statistically significant.

\section{Experience of Mental Disorders}

The students were more ready to notice and report symptoms of mental disorders when regarding friends and classmates than when concerning relatives for some symptom types (e.g., item 8 , anorexic-like behaviors) but not others (e.g., item 7, indicative of obsessive-compulsive behaviors, or item 10, on hearing voices when none is there).

The male participants were more likely than were the female participants to report their personal experiences with friends displaying apathy (Mann-Whitney's $U$-test: $z=-4.52, p<0.0001$ ), alcohol or drug abuse $(\mathrm{z}=-4.70, p<0.0001)$, and a propensity to bullying or the enjoyment of humiliating others $(\mathrm{z}=-5.41, p<0.0001)$. In addition, the male participants reported knowing classmates with alcohol or drug abuse problems $(\mathrm{z}=-3.79, p<0.0001)$ and with very odd beliefs $(z=-3.50, p<0.0001)$ more often than did the female participants. No other differences by sex were observed at the predefined threshold for statistical significance.
Age was not related to personal experience with people displaying symptoms indicative of mental disorders (Spearman's rho: $p>0.05$ or higher in all correlations, data available at request).

\section{Knowledge of Mental Disorders}

The students were able to distinguish mental and somatic disorders but were in doubt about the psychopathological nature of panic attacks and alcoholism; only half of the sample recognized them as a mental disorder (Table 3).

The male students were more likely to deny that panic attacks are a mental disorder (male students, $n=254,50.2 \%$, vs. female students, $n=192,37.1 \%$ ), and they also denied that anorexia nervosa was a mental disorder (male students, $n=77,15.2 \%$, vs. female students, $n=30,5.8 \%$ ) more often than did the female students. There were no other differences by sex (Table 3 ).

CFA was used to test the undimensional model using a scale based on corrected replies to queries concerning mental disorders (corrected reply, 1; uncorrected reply or "I do not know" reply, 0). The undimensional model proved reasonably acceptable on the basis of the fit indices: CFI, 0.900; RMSEA, 0.059 (95\% confidence interval [CI], 0.045-0.074); SRMR, 0.042. The maximal weighted internal consistency reliability for the unidimensional model was 0.588 , which approaches the threshold for acceptability of subscales derived from a questionnaire. All but two items contributed to this factor with a loading higher than 0.32 . The mean scores and factor loading on the questions concerning knowledge of mental disorders are summarized on the right-hand side of Table 3.

A summary score was then derived by summing up the number of corrected replies to the items concerning mental disorders, with corrected replies counting 1 and a potential range between 0 and 5 (two items were not included in the final global scores because of the fact that their loading on the factor was lower than 0.32).

On the measure of the knowledge of mental disorders, the mean (SD) score was 3.5 (1.2); range, 0 to 5; median, 4 (interquartile range, 2). The female students scored higher than did the male students on this measure: female students, 3.7 (1.2), vs. male students, 3.4 (1.3); Mann-Whitney's $U$-test: $z=-3.88, p<0.0001$. Age was not related to the score on the measure of knowledge of mental disorders (Spearman's $\rho=0.033, p=0.290$ ). Neither the number of visited relatives nor the number of friends seen per week was related to the scores on knowledge of mental disorders (Spearman's rho: $p>0.10$ in both correlations).

TABLE 2. General Sample Characteristics

\begin{tabular}{|c|c|c|c|}
\hline & Male Students & Female Students & Statistics \\
\hline$n(\%)$ & $506(49.5)$ & $517(50.5)$ & \\
\hline Age & & & $t=1.00, d f=1021, p=0.31$ \\
\hline Mean (SD) & $17.3(1.4)$ & $17.3(1.3)$ & \\
\hline $15-16$ yrs, $n(\%)$ & $154(30.4)$ & $164(31.7)$ & \\
\hline 17 yrs or older, $n(\%)$ & $352(69.6)$ & $353(68.3)$ & \\
\hline
\end{tabular}

GHQ

Mann-Whitney's $U$-test: $z=-5.75, p<0.0001$

Relatives visited at least once in 6 mos

Fewer than five, $n(\%)$

More than five, $n(\%)$

Friends seen at least once in a week

Fewer than five, $n(\%)$

More than five, $n(\%)$

$\begin{array}{cc}49(9.7) & 49(9.5) \\ 457(90.3) & 468(90.5) \\ 75(14.8) & 142(27.5) \\ 431(85.2) & 375(72.5)\end{array}$

$$
\chi^{2}=23.7, d f=1, p<0.0001
$$

GHQ indicates General Health Questionnaire. 
TABLE 3. Questionnaire Assessing the Knowledge of the Participants on the Name and the Characteristics of Major Mental Disorders and Their Ability to Distinguish These From Neurological or Somatic Illnesses-Total Sample, $N=1023$

\begin{tabular}{|c|c|c|c|c|c|c|}
\hline $\begin{array}{l}\text { Are Any of the Following Conditions } \\
\text { a Mental Disorder? }\end{array}$ & Yes, It Is & $\begin{array}{l}\text { No, It } \\
\text { Is Not }\end{array}$ & $\begin{array}{l}\text { I Do Not } \\
\text { Know }\end{array}$ & $\begin{array}{c}\text { Male/Female } \\
\text { Differences }\end{array}$ & Mean (SD) & $\begin{array}{c}\text { Factor Loading, } \\
\text { Unidimensional Model }\end{array}$ \\
\hline Depression & $793(78 \%)$ & $163(16 \%)$ & $67(6 \%)$ & $\chi^{2}=11.9, d f=2, p=0.003$ & $0.78(0.41)$ & 0.444 \\
\hline Panic attacks & $481(47 \%)$ & $446(44 \%)$ & $96(9 \%)$ & $\chi^{2}=17.7, d f=2, p=0.0001$ & $0.47(0.49)$ & 0.401 \\
\hline Hodgkin’s & $78(8 \%)$ & $111(11 \%)$ & $834(81 \%)$ & $\chi^{2}=5.3, d f=2, p=0.068$ & Not included & Not included \\
\hline AIDS & $36(3 \%)$ & $927(90 \%)$ & $60(6 \%)$ & $\chi^{2}=2.9, d f=2, p=0.231$ & Not included & Not included \\
\hline Schizophrenia & $934(91 \%)$ & $50(5 \%)$ & $39(4 \%)$ & $\chi^{2}=5.4, d f=2, p=0.067$ & $0.91(0.28)$ & 0.280 \\
\hline Multiple sclerosis & $157(15 \%)$ & $775(76 \%)$ & $91(9 \%)$ & $\chi^{2}=4.7, d f=2, p=0.094$ & Not included & Not included \\
\hline Social phobias & $820(80 \%)$ & $106(10 \%)$ & $97(10 \%)$ & $\chi^{2}=4.0, d f=2, p=0.132$ & $0.80(0.39)$ & 0.547 \\
\hline Cirrhosis & $40(4 \%)$ & $657(64 \%)$ & $326(32 \%)$ & $\chi^{2}=1.1, d f=2, p=0.580$ & Not included & Not included \\
\hline Alcoholism & $472(46 \%)$ & $472(46 \%)$ & $79(8 \%)$ & $\chi^{2}=4.3, d f=2, p=0.116$ & $0.46(0.49)$ & 0.302 \\
\hline Anorexia & $882(86 \%)$ & $107(11 \%)$ & $34(3 \%)$ & $\chi^{2}=28.7, d f=2, p=0.0001$ & $0.86(0.34)$ & 0.408 \\
\hline Antisocial personality & $695(68 \%)$ & $169(16 \%)$ & $159(16 \%)$ & $\chi^{2}=4.9, d f=2, p=0.084$ & $0.68(0.46)$ & 0.391 \\
\hline
\end{tabular}

Personal experience of people showing symptoms of mental disorders was not related to the measure of knowledge of mental disorders (Spearman's rho: $p>0.01$ or higher in all correlations, data available upon request).

\section{Nonstigmatizing Attitudes}

There were no differences of sex on the queries aimed at assessing beliefs and attitudes toward people diagnosed with severe mental disorders (Table 4).
A trend emerged showing that the female students were more likely than were the male students to think that people diagnosed with a severe mental disorder could be the target of violence more often than other people (Mann-Whitney's $U$-test: $z=-3.02, p=0.002$ ) and could stay in paid employment (Mann-Whitney's $U$-test: $z=-2.74$, $p=0.006$ ). However, the differences did not reach the predefined threshold for statistical significance.

About one third of the sample, irrespective of sex, reported that they thought people diagnosed with a severe mental disorder should be locked in a psychiatric hospital, and $10 \%$ to $14 \%$,

TABLE 4. Questions on Beliefs and Attitudes Toward People Diagnosed With Psychosis

\begin{tabular}{|c|c|c|c|}
\hline $\begin{array}{l}\text { "A Person With Psychosis Is Someone Who Shows Four of or More of These Problems: Odd } \\
\text { Beliefs or Ideas, Which None of His/Her Acquaintances Can Share; Hearing Voices or Seeing } \\
\text { Things Which No One Else Can Hear or See; Social Withdrawal; Severe Impairment of the } \\
\text { Ability to Study or Work; Lack of Initiative or Willingness to Do Things; Feelings of } \\
\text { Persecution or Being Victim of a Conspiracy. In Your View ..." }\end{array}$ & $\begin{array}{l}\text { Male Students } \\
\quad(n=506)\end{array}$ & $\begin{array}{l}\text { Female Students } \\
\quad(n=\mathbf{5 1 7})\end{array}$ & $\begin{array}{c}\text { Factor Loading, } \\
\text { Unidimensional Model }\end{array}$ \\
\hline $\begin{array}{l}\text { 1. How many people with psychosis can be successfully treated with } \\
\text { treatments (drugs and/or psychotherapies) that are effective } \\
\text { (i.e., they produce good results)? }\end{array}$ & & & 0.590 \\
\hline Mean (SD) on the item & $2.1(1.4)$ & $2.1(1.1)$ & \\
\hline$n(\%)$ of those who replied "a great deal or the majority" & $69(14)$ & $40(8)$ & \\
\hline 2. How many people with psychosis can recover or greatly improve? & & & 0.673 \\
\hline Mean $(\mathrm{SD})$ on the item & $2.5(1.3)$ & $2.5(1.1)$ & \\
\hline$n(\%)$ of those who replied "a great deal or the majority" & $105(21)$ & $76(15)$ & \\
\hline 3. How many people with psychosis could be dangerous? & & & 0.500 \\
\hline Mean $(\mathrm{SD})$ on the item & $2.9(1.4)$ & $2.9(1.4)$ & \\
\hline$n(\%)$ of those who replied "a great deal or the majority" & $70(14)$ & $54(10)$ & \\
\hline $\begin{array}{l}\text { 4. How many people with psychosis could become the victim } \\
\text { of harassment or violence from "non-sufferers"? }\end{array}$ & & & 0.343 \\
\hline Mean (SD) on the item & $2.4(1.3)$ & $2.6(1.3)$ & \\
\hline$n(\%)$ of those who replied "a great deal or the majority" & $96(19)$ & $122(24)$ & \\
\hline $\begin{array}{l}\text { 5. How many people with psychosis should have a job, when able, } \\
\text { and be given the chance to make themselves useful? }\end{array}$ & & & 0.437 \\
\hline Mean (SD) on the item & $2.8(1.6)$ & $3.1(1.5)$ & \\
\hline$n(\%)$ of those who replied "a great deal or the majority" & $189(37)$ & $224(43)$ & \\
\hline $\begin{array}{l}\text { 6. How many people with psychosis should be subjected to } \\
\text { long-term treatments in a closed psychiatric hospital rather than at home? }\end{array}$ & & & 0.386 \\
\hline Mean $(\mathrm{SD})$ on the item & $2.4(1.6)$ & $2.6(1.5)$ & \\
\hline$n(\%)$ of those who replied "a great deal or the majority" & $166(33)$ & $180(35)$ & \\
\hline
\end{tabular}


according to sex, reported that most people diagnosed with psychosis can be dangerous, whereas another 34\% thought that a large fraction, albeit not the majority, of people with psychosis can be dangerous. Conversely, about $10 \%$ thought that the treatment of severe mental disorders could be effective for most affected patients, and only $30 \%$ thought that this could be effective for a fraction of them, whereas around $40 \%$ of the sample believe that treatment is effective for few patients or none (20\% ticked the "do not know" option on the query). A similar skeptical attitude was recorded on the query concerning the chances of a full recovery.

The undimensional model applied to this questionnaire proved reasonably acceptable on the basis of the fit indices: CFI, 0.954; RMSEA, 0.067 (95\% CI, 0.49-0.085); SRMR, 0.038. The maximal weighted internal consistency reliability for the unidimensional model was 0.691 . All items contributed to the factor with a loading higher than 0.32 . The mean scores and factor loading on the six questions concerning beliefs and attitudes toward people diagnosed with psychosis are summarized in Table 4.

In the sample, the mean (SD) score on this measure of nonstigmatizing attitudes was 15.6 (5.1), with a range from 0 to 26 and a median of 16 (interquartile range, 6).

The male and female students did not differ on the global measure of nonstigmatizing attitudes: mean (SD), 15.2 (5.6) vs. 15.9 (4.5), respectively, Mann-Whitney's $U$-test: $z=-1.55, p=0.120$.

Age was not related to the global measure of nonstigmatizing attitudes (Spearman's $\rho=0.061, p=0.050$ ); the number of relatives visited or the number of friends seen per week was not related to the global measure of nonstigmatizing attitudes (Spearman's rho: $p>0.10$ in both correlations).

Personal experience with people showing symptoms of mental disorders was not related to nonstigmatizing attitudes (Spearman's rho: $p>0.01$ or higher in all correlations, data available at request). However, there was a trend for more positive, nonstigmatizing attitudes in those who had a family history of psychosis (i.e., one or more relatives with hallucinations, psychotic-like beliefs, and/or paranoid thinking): Spearman's $\rho=0.102, p=0.001$.

\section{Willingness to Provide Help}

In the sample, 584 students (57\%) declared themselves to be willing to provide help to someone with a mental disorder. More female $(n=341,66 \%)$ than male $(n=243,48 \%)$ students reported to be willing to provide help to someone with a mental disorder: $\chi^{2}=32.84, d f=1, p<0.0001$. The students who reported to be willing to provide help to someone with a mental disorder did not differ from those who denied their willingness to provide help to someone with a mental disorder $(n=439 ; 43 \%)$ as far as age was concerned: 17.3 (1.3) vs. $17.3(1.3), t=0.145, d f=1021, p=0.88$.

Willingness to provide help to someone with a mental disorder was not related to the number of relatives visited or the number of friends seen weekly (Mann-Whitney's $U$-test: $p>0.01$ in both comparisons).

Personal experience with people showing symptoms of low self-esteem or phobia in relatives, friends, or classmates was positively related to willingness to provide help to someone with a mental disorder (Spearman's $\rho>0.130, p<0.0001$, in all correlations). Willingness to provide help was also positively associated with family history of psychosis (Spearman's $\rho=0.129, p<0.0001$ ).

\section{Knowledge of Mental Disorders, Stigma, and Willingness to Provide Help}

The scores on the measure of knowledge of mental disorders were positively related to the scores on the global measure of nonstigmatizing attitudes: Spearman's $\rho=0.136, p<0.0001$.

Those who were willing to provide help to someone with a mental disorder had a higher score on the measure of knowledge of mental disorders than did those who were not willing: 3.7 (1.2) vs. 3.4 (1.2), Mann-Whitney's $U$-test: $z=-3.66, p<0.0001$. Those who were willing to provide help to someone with a mental disorder also reported more favorable attitudes toward those diagnosed with psychosis than did those who were not willing: 16.4 (4.6) vs. 14.5 (5.4), Mann-Whitney's $U$-test: $z=-5.84, p<0.0001$.

\section{DISCUSSION}

This study proved that, for Italian high school students, the knowledge of mental disorders was positively correlated with the willingness to provide help to someone with a mental disorder, and both were related to more positive attitudes toward people with psychosis. This is a confirmation that, as in past studies, mental health literacy is related to both lower stigma toward and reduced social distance from people with severe mental disorders (EvansLacko et al., 2010; Jorm, 2012; Jorm et al., 1997).

The students had a reasonable knowledge of mental disorders and were generally able to distinguish these from somatic disorders. However, they had doubts on the psychopathological nature of disorders such as panic attacks and alcohol dependence.

There is some evidence that people tend to blame and attribute responsibility to those with conditions such as alcohol abuse (Angermeyer et al., 2011; Link et al., 2004; Schomerus et al., 2011). One can deduce that the students might have perceived alcohol dependence as depending on the subject's actions and will more than on other mental disorders (Schomerus et al., 2011). Therefore, they would have been less likely to consider alcohol abuse as a mental disorder, that is, an illness, which is generally considered to be something that happens to a person and not the consequence of a person's choice or actions. However, the students might have been less informed on the current conceptualization of alcohol abuse as a psychopathology. As for panic attacks, these might have been considered somehow "normal" in both personal and peer experiences and equated to situational anxiety, so a portion of the participants might have overlooked the pathological nature of a panic attack.

Despite the observed connections between mental health literacy and positive attitudes toward people with psychosis, a large portion of the students held some misconception of mental disorders: about $33 \%$ of the sample thought that people diagnosed with a severe mental disorder should be treated in closed psychiatric hospitals rather than in a general hospital or at home, and $40 \%$ of the sample hold the belief that a large portion of people diagnosed with severe mental disorders can be dangerous. The students were also rather skeptical about the effectiveness of treatment or the chance of recovery for people with severe mental disorders. These misconceptions are rather common (Byrne, 1999; ten Have et al., 2010; Watson et al., 2005); medical and nursing students, too, were reported to hold the idea that people diagnosed with mental disorders are unlikely to recover and that they can be dangerous and violent (Aker et al., 2007; Llerena et al., 2002).

The ideas about the dangerousness of people with severe mental disorders can reinforce rejection and distance, both factors that can increase discrimination and marginalization caused by stigma (Angermeyer et al., 2011; Angermeyer and Matschinger, 2003; Link and Cullen, 1986; Pescosolido et al., 1999). In this study, those with higher stigma scores were also less willing to provide help to someone with a mental disorder. Misconceptions about mental disorders have additional negative consequences for those who hold them. Indeed, fear of marginalization can enforce self-stigmatization in people with an evolving mental disorder (Rüsch et al., 2010), also reducing access to care. Moreover, internalized stigma reduces selfesteem (Link et al., 1987; Lysaker et al., 2008), and this may have a further negative impact on treatment compliance. Skepticism about the effectiveness of available treatments is another factor that can delay access to care when in need. 
Contrary to expectations, age was not related to the knowledge of mental disorders or stigma or willingness to provide help to someone with a mental disorder. The age range in the investigated sample was small, and this may have limited the possibility to identify relevant differences related to age on the measures used in this study.

The female students showed greater knowledge of mental disorders than did the male students. Nevertheless, no relevant sex differences were seen in the attitudes toward those with mental illness, a finding consistent with past studies (Holzinger et al., 2012, but different findings in Jorm and Wright, 2008). However, it is remarkable that about half of the students reported their willingness to provide help to someone with a mental disorder when in need. The female students were more likely than were the male students to volunteer support to people with mental disorders, as observed in past studies (Holzinger et al., 2012). In addition, as in previous studies (Olsson and Kennedy, 2010), greater mental health literacy was linked to a higher willingness to provide help to people with mental disorders.

Personal experience of people with symptoms indicative of mental disorders was not related to knowledge of mental disorders or stigma toward those with psychosis. Nevertheless, a trend emerged associating higher scores on the measure of nonstigmatizing attitudes to those who had a family history of psychosis. A willingness to provide help to someone with a mental disorder was also positively associated with a family history of psychosis. This may indicate that direct exposure to psychosis can lower stigma and reduce social distance from those with mental disorder. Indeed, in past studies, contact with a person diagnosed with a mental disorder was inversely related to endorsing psychiatric stigma (Pinfold et al., 2003; Schulze et al., 2003; Thornicroft et al., 2008).

\section{Limitations and Strengths of This Study}

To enroll as large a sample as possible, the questionnaires were used to assess the participants' attitudes and beliefs; pen-and-paper assessments bear limitations in capturing behavioral responses and behavior-based attitudes (i.e., social distance). Moreover, tools based on self-reporting are open to a social desirability bias, and this might have inflated favorable scores on the stigma measure. Nevertheless, the study involved a large and representative sample of high school students: nearly $4 \%$ of the people of the same age and sex in a designated area and a very high participation rate.

\section{CONCLUSIONS}

The questionnaires used in this study and selected to measure knowledge of mental disorders and beliefs and attitudes toward people diagnosed with psychosis showed acceptable reliability and also internal validity, as far as interrelations in the expected direction were concerned. These provide a valid and a reliable measure of mental health literacy in the sample. In this study, mental health literacy was found to be related to more favorable attitudes toward people with psychosis and a greater willingness to provide help to someone with a mental disorder, as expected, on the basis of the a priori hypotheses. These findings support the idea that educational interventions aimed at increasing mental health literacy in young people will be effective in reducing negative beliefs and attitudes toward people with severe mental disorders (Evans-Lacko et al., 2010; Jorm, 2012).

\section{DISCLOSURES}

$\operatorname{Dr}$ A. Lai and Dr M. Serra have received financial support from the Regione Autonoma della Sardegna (Grant CRP2_356, PO Sardegna FSE 2007-2013, in accordance with the regional law L.R. 7/2007 "Promozione della ricerca scientifica e dell'innovazione tecnologica in Sardegna"). The Regione Sardegna had no further role in the design of this study; in the collection, analysis, and interpretation of data; in the writing of the report; or in the decision to submit the article for publication. No other forms of financial support were received for this study. The authors declare no conflict of interest.

\section{REFERENCES}

Aker S, Aker AA, Boke O, Dundar C, Sahin AR, Peksen Y (2007) The attitude of medical students to psychiatric patients and their disorders and the influence of psychiatric study placements in bringing about changes in attitude. Isr J Psychiatry Relat Sci. 44:204-212.

Angermeyer MC, Holzinger A, Carta MG, Schomerus G (2011) Biogenetic explanations and public acceptance of mental illness: Systematic review of population studies. Br J Psychiatry. 199:367-372.

Angermeyer MC, Matschinger H (2003) The stigma of mental illness: Effects of labelling on public attitudes towards people with mental disorder. Acta Psychiatr Scand. 108:304-309.

Angermeyer MC, Matschinger H (1997) Social distance towards the mentally ill: Results of representative surveys in the Federal Republic of Germany. Psychol Med. 27:131-141.

Bentler PM (2008) EQS 6.1 Structural equations program manual. Encino, CA: Multivariate Software.

Bland JM, Altman DG (1997) Statistics notes: Cronbach's alpha. Br Med J. 314:572.

Browne MW, Cudeck R (1993) Alternative ways of assessing model fit. In Bollen KA, Long JS (Eds), Testing structural equation models (pp 136-161). Newbury Park, CA: Sage.

Buizza C, Pedrini L, Pioli R (2010) "Apri le porte e libera la mente": Un percorso di sensibilizzazione verso i disturbi mentali rivolto a studenti e insegnanti di una scuola superiore nella città di Brescia. Errepiesse. 4:16-25.

Buizza C, Schulze B, Bertocchi E, Rossi G, Ghilardi A, Pioli R (2007) The stigma of schizophrenia from patients' and relatives' view: A pilot study in an Italian rehabilitation residential care unit. Clin Pract Epidemiol Ment Health. 3:23.

Byrne P (1999) Stigma of mental illness. Br J Psychiatry. 174:1-2.

Castaldelli-Maia JM, Scomparini LB, Andrade AG, Bhugra D, de Toledo Ferraz Alves TC, D'Elia G (2011) Perceptions of and attitudes toward antidepressants: Stigma attached to their use-A review. J Nerv Ment Dis. 199:866-871.

Chandra A, Minkovitz CS (2006) Stigma starts early: Gender differences in teen willingness to use mental health services. J Adolesc Health. 38:754.e1-e8.

Comrey AL (1973) A first course in factor analysis. New York: Academic Press.

Corrigan P (2004) How stigma interferes with mental health care. Am Psychol. 59:614-625.

Corrigan PW, River LP, Lundin RK, Penn DL, Uphoff-Wasowski K, Campion J, Mathisen J, Gagnon C, Bergman M, Goldstein H, Kubiak MA (2001) Three strategies for changing attributions about severe mental illness. Schizophr Bull. 27:187-195.

Costello EJ, Angold A, Keeler GP (1999) Adolescent outcomes of childhood disorders: The consequences of severity and impairment. J Am Acad Child Adolesc Psychiatry. 38:121-128.

Eisenberg D, Downs MF, Golberstein E, Zivin K (2009) Stigma and help seeking for mental health among college students. Med Care Res Rev. 66:522-541.

Evans-Lacko S, Little K, Meltzer H, Rose D, Rhydderch D, Henderson C, Thornicroft G (2010) Development and psychometric properties of the Mental Health Knowledge Schedule. Can J Psychiatry. 55:440-448.

Fröjd S, Marttunen M, Pelkonen M, von der Pahlen B, Kaltiala-Heino R (2007) Adult and peer involvement in help-seeking for depression in adolescent population. Soc Psychiatry Psychiatr Epidemiol. 42:945-952.

Goldberg DP (1972) The detection of psychiatric illness by questionnaire. London: Oxford University Press.

Gonzalez JM, Alegria M, Prihoda TJ (2005) How do attitudes toward mental health treatment vary by age, gender, and ethnicity/race in young adults? J Community Psychol. 33:611-629.

Griffiths KM, Christensen H, Jorm AF (2008) Predictors of depression stigma. BMC Psychiatry. 8:25

Holzinger A, Floris F, Schomerus G, Carta MG, Angermeyer MC (2012) Gender differences in public beliefs and attitudes about mental disorder in western countries: A systematic review of population studies. Epidemiol Psychiatr Sci.21:73-85

Hu L, Bentler PM (1999) Cutoff criteria for fit indices in covariance structure analysis: Conventional criteria versus new alternatives. Struct Equ Modeling. $6: 1-55$. 
Jenkins JH, Carpenter-Song EA (2009) Awareness of stigma among persons with schizophrenia: Marking the contexts of lived experience. J Nerv Ment Dis. 197:520-529.

Jorm AF (2012) Mental health literacy: Empowering the community to take action for better mental health. Am Psychol.67:231-243.

Jorm AF, Korten AE, Jacomb PA, Christensen H, Rodgers B, Pollitt P (1997) "Mental health literacy": A survey of the public's ability to recognise mental disorders and their beliefs about the effectiveness of treatment. Med J Aust. 166:182-186.

Jorm AF, Wright AM (2008) Influences on young people's stigmatising attitudes towards peers with mental disorders: National survey of young Australians and their parents. Br J Psychiatry. 192:144-149.

Katki HA (2008) Invited commentary: Evidence-based evaluation of p values and Bayes factor. Am J Epidemiol. 168:384-388.

Kelly CM, Jorm AF, Wright A (2007) Improving mental health literacy as a strategy to facilitate early intervention for mental disorders. Med J Aust. 187: S26-S30.

Kessler RC, Amminger GP, Aguilar-Gaxiola S, Alonso J, Lee S, Ustün TB (2007) Age of onset of mental disorders: A review of recent literature. Curr Opin Psychiatry. 20:359-364.

Kim-Cohen J, Caspi A, Moffitt TE, Harrington H, Milne BJ, Poulton R (2003) Prior juvenile diagnoses in adults with mental disorder: Developmental follow-back of a prospective-longitudinal cohort. Arch Gen Psychiatry. 60: 709-717.

Link BG, Cullen FT (1986) Contact with the mentally ill and perceptions of how dangerous they are. J Health Soc Behav. 27:289-302.

Link BG, Cullen FT, Frank J, Wozniak JF (1987) The social rejection of former mental patients: Understanding why labels matter. Am J Sociol. 92:1461-1500.

Link BG, Yang LH, Phelan JC, Collins PY (2004) Measuring mental illness stigma. Schizophr Bull. 30:511-541.

Llerena A, Caceres MC, Penas-LLedo EM (2002) Schizophrenia stigma among medical and nursing undergraduates. Eur Psychiatry. 17:298-299.

Lysaker PH, Tsai J, Yanos P, Roe D (2008) Associations of multiple domains of self-esteem with four dimensions of stigma in schizophrenia. Schizophr Res. 98:194-200.

Mirabella F, Del Re D, Palumbo G, Cascavilla I, Gigantesco A (2010) A handbook to promote mental health, psychological well-being and emotional intelligence in secondary schools: Evaluation of likeliness and usefulness [in Italian]. G Ital Psicopatol. 16:362-369.

Mukolo A, Heflinger CA, Wallston KA (2010) The stigma of childhood mental disorders: A conceptual framework. J Am Acad Child Adolesc Psychiatry. 49:92-103.

Norman RMG, Sorrentino RM, Windell D, Manchanda R (2008) The role of perceived norms in the stigmatization of mental illness. Soc Psychiatry Psychiatr Epidemiol. 43:851-859.

Nunnally JC (1978) Psychometric theory (2nd ed). New York: McGraw-Hill.

Olsson DP, Kennedy MG (2010) Mental health literacy among young people in a small US town: Recognition of disorders and hypothetical helping responses. Early Interv Psychiatry. 4:291-298.

Patton GC, Hetrick SE, McGorry P (2007) Service responses for youth onset mental disorders. Curr Opin Psychiatry. 20:319-324.

Penn DL, Guynan K, Daily T, Spaulding WD, Garbin CP, Sullivan M (1994) Dispelling the stigma of schizophrenia: What sort of information is best? Schizophr Bull. 20:567-578.

Pescosolido BA, Martin JK, Lang A, Olafsdottir S (2008) Rethinking theoretical approaches to stigma: A framework integrating normative influences on stigma (FINIS). Soc Sci Med. 67:431-440.

Pescosolido BA, Monahan J, Link BG, Stueve A, Kikuzawa S (1999) The public's view of the competence, dangerousness, and need for legal coercion of persons with mental health problem. Am J Public Health. 89:1339-1345.

Pinfold V, Toulmin H, Thornicroft G, Huxley P, Farmer P, Graham T (2003) Reducing psychiatric stigma and discrimination: Evaluation of educational interventions in UK secondary schools. Br J Psychiatry. 182:342-346.

Pingani L, Forghieri M, Ferrari S, Ben-Zeev D, Artoni P, Mazzi F, Palmieri G, Rigatelli M, Corrigan PW (2012) Stigma and discrimination toward mental illness: Translation and validation of the Italian version of the attribution questionnaire-27 (AQ-27-I). Soc Psychiatry Psychiatr Epidemiol.47:993-999.

Pinto-Foltz MD, Logsdon MC (2009) Conceptual model of research to reduce stigma related to mental disorders in adolescents. Issues Ment Health Nurs. 30:788-795

Quinn N, Wilson A, MacIntyre G, Tinklin T (2009) 'People look at you differently': Students' experience of mental health support within higher education. Br J Guidance Couns. 37:405-418.

Rüsch N, Corrigan PW, Todd AR, Bodenhausen GV (2010) Implicit self-stigma in people with mental illness. J Nerv Ment Dis. 198:150-153.

Rutz W (2001) Mental health in Europe: Problems, advances and challenges. Acta Psychiatr Scand. 104(suppl 410):15-20.

Sakellari E, Leino-Kilpi H, Kalokerinou-Anagnostopoulou A (2011) Educational interventions in secondary education aiming to affect pupils' attitudes towards mental illness: A review of the literature. J Psychiatr Ment Health Nurs. 18:166-176.

Schomerus G, Lucht M, Holzinger A, Matschinger H, Carta MG, Angermeyer MC (2011) The stigma of alcohol dependence compared with other mental disorders: A review of population studies. Alcohol Alcohol. 46:105-112.

Schulze B, Richter-Werling M, Matschinger H, Angermeyer MC (2003) Crazy? So what! Effects of a school project on students' attitudes towards people with schizophrenia. Acta Psychiatr Scand. 107:142-150.

Sorsdahl KR, Stein DJ (2010) Knowledge of and stigma associated with mental disorders in a South African community sample. J Nerv Ment Dis. 198:742-747.

Tanaka JS (1993) Multifaceted conceptions of fit in structural equation models. In Bollen KA, Long JS (Eds), Testing structural equation models (pp. 10-39). Newbury Park, CA: Sage.

ten Have M, de Graaf R, Ormel J, Vilagut G, Kovess V, Alonso J (2010) Are attitudes towards mental health help-seeking associated with service use? Results from the European study of Epidemiology of Mental Disorders. Soc Psychiatry Psychiatr Epidemiol. 45:153-163.

Thornicroft G (2008) Stigma and discrimination limit access to mental health care. Epidemiol Psichiatr Soc. 17:14-19.

Thornicroft G, Brohan E, Kassam A, Lewis-Holmes E (2008) Reducing stigma and discrimination: Candidate interventions. Int J Ment Health Syst. 2:3

Thornicroft G, Rose D, Kassam A, Sartorius N (2007) Stigma: Ignorance, prejudice or discrimination? Br J Psychiatry. 190:192-193.

Yamaguchi S, Mino Y, Uddin S (2001) Strategies and future attempts to reduce stigmatization and increase awareness of mental health problems among young people: A narrative review of educational interventions. Psychiatry Clin Neurosci. 65:405-415.

Yap MB, Jorm AF (2011) The influence of stigma on first aid actions taken by young people for mental health problems in a close friend or family member: Findings from an Australian national survey of youth. J Affect Disord. 134:473-477.

van Zelst C (2009) Stigmatization as an environmental risk in schizophrenia: A user perspective. Schizophr Bull. 35:293-296.

Vezzoli R, Archiati L, Buizza C, Pasqualetti P, Rossi G, Pioli R (2001) Attitude towards psychiatric patients: A pilot study in a northern Italian town. Eur Psychiatry. 16:451-458.

Wang J, Fick G, Adair C, Lai D (2007) Gender specific correlates of stigma toward depression in a Canadian general population sample. J Affect Disord. 103:91-97.

Warner R (2008) Implementing local projects to reduce the stigma of mental illness. Epidemiol Psichiatr Soc. 17:20-25.

Watson AC, Miller FE, Lyons JS (2005) Adolescent attitudes toward serious menal illness. J Nerv Ment Dis. 193:769-772.

Wolff G, Pathare S, Craig T, Leff J (1996) Community knowledge of mental illness and reaction to mentally ill people. Br J Psychiatry. 168:191-198.

World Psychiatric Association (2000) The WPA programme to reduce stigma and discrimination because of schizophrenia (Vols 1-5). Geneva, Switzerland: World Psychiaric Association. 